\title{
Effects of Vitamin C on High Blood Pressure Induced by Salt in Spontaneously Hypertensive Rats
}

\author{
Yoshiyuki NishikAWA ${ }^{1}$, Kaori TATSUMI ${ }^{1}$, Takeshi MATSUURA ${ }^{1}$, \\ Ayako YAMAMOTO ${ }^{1}$, Tomonori NADAMOTO ${ }^{2}$ and Kimiko URABE ${ }^{2}$ \\ ${ }^{1}$ Laboratory of Food Science and Nutrition, College of Nutrition, Koshien University, \\ 10-1 Momijigaoka, Takarazuka 665-0006, Japan \\ ${ }^{2}$ Food Science and Nutrition Course, Department of Lifestyle Studies, School of Human Culture, University of \\ Shiga Prefecture, 2500 Hassaka-cho, Hikone 522-8533, Japan
}

(Received February 25, 2003)

\begin{abstract}
Summary By breeding and feeding salt to spontaneously hypertensive rats (SHR) continuously over a long period (until $60 \mathrm{wk}$ old), rats with systolic blood pressures (SBP) of over $270 \mathrm{mmHg}$ were prepared. It was studied whether or not supplying large amounts of vita$\min \mathrm{C}(200 \mathrm{mg} / \mathrm{rat} / \mathrm{d})$ over this period might bring any beneficial effect to blood pressure. Moreover, physico-chemical studies were performed to measure the components and enzymes in the blood and urine at 53 and 60 wk-old, and biochemical studies on vitamin C were also carried out in this experiment. Male (14 rats: 7 wk-old, 100-105 g) and female (15 rats: 7 wk-old, 95-100 g) SHR were divided into three groups and bred continuously for $53 \mathrm{wk}$. The A group rats were given salt $(2.5 \mathrm{~g} / 100 \mathrm{~g}$ of diet), the B group rats were given salt and vitamin $\mathrm{C}(500 \mathrm{mg} / 100 \mathrm{~mL}$ of drinking water), and the $\mathrm{C}$ group rats were controls. The results showed almost the same tendencies between male and female rats. The body weights of the SHR in groups A and B were slightly lower than group C. The amount of food intake in groups A and B was almost the same as group C. The amount of water intake was, in the order from highest to lowest, group A, B and C. The SBP of group A rats exhibited the highest value among the three groups. The SBP of group B rats given vitamin $\mathrm{C}$ simultaneously with the salt resulted in a low blood pressure level close to that of the controls (group C). Furthermore, the DBP (diastolic blood pressure) also reflected the antihypertensive effect of vitamin $\mathrm{C}$ as well. The heartbeat of the rats was highest in group $\mathrm{A}$, and was comparable to the value in the rats receiving vitamin $C$ simultaneously with salt. For the tests on occult blood and protein in the urine, group A rats showed strong positive reactions, whereas the group $\mathrm{B}$ and $\mathrm{C}$ rats had decreased results for both tests. The organ weights of the liver, stomach, spleen, adrenal gland and kidneys per $100 \mathrm{~g}$ rat body weight were not different among the three groups. The values for the bilirubin content, and the enzyme activities of ALT and AST in the blood showed to be the highest in the male rats of group A. The values from the group $B$ rats decreased near to the normal value like the control group. Vitamin C was found to decrease the blood pressure in SHR, and also to work effectively to protect liver and kidney functions even under the condition of very high blood pressure, as high as $250 \mathrm{mmHg}$.
\end{abstract}

Key Words vitamin C, ascorbic acid, salt, blood pressure, spontaneously hypertensive rat

The three main causes of death in Japan are malignant tumors, heart disease and cerebrovascular disease. The latter two result directly from disorders related to blood circulation. The European lifestyle, which has a high lipid intake, has an increased incidence of arteriosclerosis and increased rate of death due to heart and cerebral diseases. Hypertension is brought about by arteriosclerosis, and conversely hypertension

E-mail: nishizen@nike.eonet.ne.jp

Abbreviations: SHR, spontaneously hypertensive rats; SBP, systolic blood pressure; DBP, diastolic blood pressure; ALT, alanine aminotransferase; AST, aspartic acid aminotransferase; GLU, glucose; BUN, blood urea nitrogen; T-Bil, total bilirubin; T-cho, total cholesterol. also accelerates arteriosclerosis. Hypertension in human beings can be classified into two groups: essential hypertension and secondary hypertension, which are induced by diseases of the renal, adrenal or parathyroid glands. The blood pressure increases via contraction of the smooth muscle of the peripheral arterioles. When high blood pressure continues for a long period, it is pathologic-physiologically termed hypertension. Hypertension is one of the major risk factors for arteriosclerosis, and induces cerèbral embolism, stroke and ischemic heart disease (1-3). Many epidemical studies have shown that the death rate caused by these three diseases based on arteriosclerosis was lower in areas where the population ate lots of vegetables and fruits containing abundant antioxidants $(4,5)$. The cytopro- 
tective actions of vitamin $\mathrm{C}$ can limit plaque instability. in advanced atherosclerosis (6-8). Vitamin $\mathrm{C}$ is thought to spare the glutathion in vascular cells exposed to oxidatively modified LDLs, thus attenuating the adaptive responses in antioxidant gene expression and protecting the cells against apoptotic cell death (9). Yoshioka et al. (10) carried out an epidemiological investigation using 1,931 volunteers living in Kagoshima Prefecture, Japan, and found that hypertensive patients had lower serum vitamin $\mathrm{C}$ levels than the normaltensive patients, who had high vitamin $C$ levels in their serum. Furthermore, it was shown that blood serum vitamin $\mathrm{C}$ levels of over $1 \mathrm{mg} / 100 \mathrm{~mL}$ in males and over $1.2 \mathrm{mg} / 100 \mathrm{~mL}$ in females were needed for the prevention of hypertension. The vitamin $\mathrm{C}$ intake of hypertensive patients has generally been reported to be limited (11-13), and the death rate due to stroke is closely but inversely correlated with the increasing intake of vitamin C (14-16). Pretreatment with vitamin C (20-100 mg/kg) in rabbit (Oryctolagus cuniculus) may also attenuate the blood pressure increase induced by the intake of exogenous noradrenalin (17). On the other hand, there have been epidemiological studies on 87,000 female nurses and 4,000 male health professionals that found almost no effect of vitamin $\mathrm{C}$ from diets or as supplements on cardiovascular risk (18). Spontaneously hypertensive rat (SHR) (19) and stroke-prone spontaneously hypertensive rat (SHR-sp) $(20,21)$, which have inherited hypertension even in youth, have been used as models in experiments for high blood pressure and metabolism, and have been used as an animal models for primary hypertension. Generally, the excessive consumption of salt has been reported to induce hypertension and lead to arteriosclerosis, heart disease and blood-vessel disor$\operatorname{der}(22,23)$. However, there is a study reporting that high blood pressure is not correlated with dietary salt. It has recently been proposed that the difference in the sensitivity to salt is caused by multiple genetic patterns (24). It has been studied whether or not $\mathrm{Na}^{+}$or $\mathrm{Cl}^{-}$ions are mainly responsible for high blood pressure (25). There have been two different discussions regarding the effects of salt and vitamin $\mathrm{C}$ on the increment or suppression of high blood pressure. Accordingly, to clearly determine if the excessive intake of salt can increase blood pressure and if vitamin $\mathrm{C}$ is effective in decreasing this high blood pressure, we carried out experiments using SHR. Vitamin C had been reported to be effective in attenuating high blood pressure. However, treatments with vitamin $C$ have not been carried out clinically using high blood pressure patients. To investigate whether or not vitamin $C$ plays a role in patients with high blood pressure disease in a clinical setting, this experiment was designed. There are three novel points to this research: (1) The preparation of rats with blood pressures of $270 \mathrm{mmHg}$; (2) the continuous breeding of these rats for a long period (over $1 \mathrm{y}$ ) to confirm the effect of vitamin $C$; and (3) examining the changes in the physiological conditions of the rats with high blood pressure.

\section{MATERIALS AND METHODS}

1. Physiological experiments by giving salt and vitamin $C$ (V.C) to SHR. Male spontaneously hypertensive rats (SHR) (14 rats: 7 wk-old, 100-105 g) and female SHR (15 rats: 7 wk-old, 95-100 g), which were bred in our laboratory after being obtained from Shimizu Animal (Kyoto, Japan), were divided into three groups (4-5 rats per group), from $\mathrm{A}$ to $\mathrm{C}$, and housed in individual wire screen-bottomed cages. The group A rats were given salt (Japan Tobacco Industry, NaCl: $99.8 \%$ ) at $2.5 \mathrm{~g}$ per $100 \mathrm{~g}$ diet. The group $\mathrm{B}$ rats were given salt and vitamin C (V.C, $500 \mathrm{mg} / 100 \mathrm{~mL}$ water) and the group C rats were controls. The salt was added to the diet because of adding V.C to the drinking water. The rats were given the indicated diets with salt and drinking water containing V.C every day until 60 wk-old. The animal room was maintained at $25^{\circ} \mathrm{C}$ with a $12 \mathrm{~h}$ light cycle (7:00-19:00) in a SPF environment. The rats were allowed free access to water and a stock chow diet (Clea Japan, CE2). The body weights of the rats and their diet and drinking water intakes were measured 23 times per week. The systolic blood pressure (SBP) and diastolic blood pressure (DBP) of the rats were measured using a sphygmomanometer (MK-1030, Muromachi Machine Industry, Japan). Several urine examinations of the SHR were carried out at 53 wk-old using screening Tes-tapes (Wako Pure Chemical Industries, Japan).

2. Biochemical experiments by giving salt and vitamin $C$ to SHR. At $60 \mathrm{wk}$-old, the rats were dissected, their livers, spleens and stomachs were removed, and the organ weights were determined. The evolution of gastric ulcers in the rats was observed by the method described below. Several blood biochemical tests were carried out on the serum of the rats. ALT (alanine aminotransferase: GPT), AST (aspartic acid aminotransferase: GOT), GLU (glucose), BUN (blood urea nitrogen), TBil (total bilirubin) and T-cho (total cholesterol) were assayed to measure the biological functions of SHR. The amount of salt given to the rats was about 10 times that for a normal human being. This was determined by converting the body weight of the rat to that of a human. Vitamin C (500 mg) was dissolved in water (100 $\mathrm{mL}$ ), and the amount ingested by the rat was about 20 100 times the amount given to a human as described above.

3. Assay and gastric ulcer index. The lumen of the removed stomach was washed by passing physiological saline solution from the pylorus to the cardio using a syringe. Sections of the pylorus and cardio of the washed stomach were tied with threads, and the stomach was filled with $1 \%$ formalin and immersed in $10 \%$ formalin for $10 \mathrm{~min}$ to fix the gastric ulcer. The stomach was incised along the greater curvature and examined histopathologically using a light microscope (Olympus, Japan, SZN).

4. Assay and biochemical test for blood and urine. Several kinds of urine tests, such as ulobilinogen, occult blood, bilirubin, ketone bodies, glucose dextrose, pro- 
tein, $\mathrm{pH}$, white blood cells, specific gravities and ascorbic acid, were carried out using Tes-tape. The biochemical indices for blood drawn from the abdominal aorta were measured using an autoanalyzer (Kyoto Daiichi, Japan, SP-4410).

5. Ethical approval. This study was carried out according to the guidelines for animal experiments of the Journal of Nutritional Science and Vitaminology, and also that of The College of Nutrition, Koshien University.

6. Data analysis. The data were presented as means $\pm \mathrm{SD}(n=4$ or 5$)$. Comparisons of the data among three groups were done using the multiple range method of Duncan (26).

\section{RESULTS}

1. Effects of salt and vitamin $C$ on the body weight and dietary intake of food and water by SHR

As shown in Fig. 1, the body weights of the SHR given salt (JT salt) or salt and vitamin C until 60 wk-old were slightly lower than those of the control rats for both males (Fig. 1A) and females (Fig. 1B). The amount of food ingested by the rats given salt or salt and vitamin C was almost the same as the control rats for both sexes (Fig. 2). On the other hand, the amount of water intake showed high values in the order of group A, group B, and group C. Significant differences were observed between the three groups for female rats (Fig. 3).

2. Effects of salt and vitamin $\mathrm{C}$ on the blood pressure and pulse of SHR

The systolic and diastolic blood pressures (SBP and DBP, respectively) of SHR were measured constantly until 60 wk-old. The SBP of the rats given only salt exhibited the highest value among the three groups throughout the experimental period until 60 wk-old for both sexes as shown in Fig. 4. In female rats, the SBP of the rats receiving vitamin $\mathrm{C}$ simultaneously with salt was close to that of the controls. Furthermore, the DBP of SHR also reflected a beneficial effect of vitamin C for both sexes as shown in Fig. 5. Thus the effectiveness of vitamin C in lowering SBP and DBP was therefore confirmed by these experiments. The heartbeat of SHR, in parallel with the blood pressure, was the highest in the rats receiving only salt. By simultaneously giving vitamin $\mathrm{C}$ with the salt, the heartbeat became almost comparable to that of the control rats for both sexes (Fig. 6).

3. Effects of salt and vitamin $C$ on the biological parameters of the urine of SHR

As shown in Table 1, the values for urobilinogen, bilirubin, ketone bodies, glucose dextrose, $\mathrm{pH}$ and specific gravity in the urine were normal even in the case of the JT salt rat group. Occult blood was not detected in the control SHR, but groups A and B, which were given salt, showed a positive reaction, especially the A group rats. Protein in the urine was detected even in the control SHR rats, and the rats given salt showed a stronger reaction for both sexes. Accordingly, the occult blood and protein values in the urine decreased in the order of control group, the salt and vitamin C group and the salt group. Although normal Wistar rats show a negative
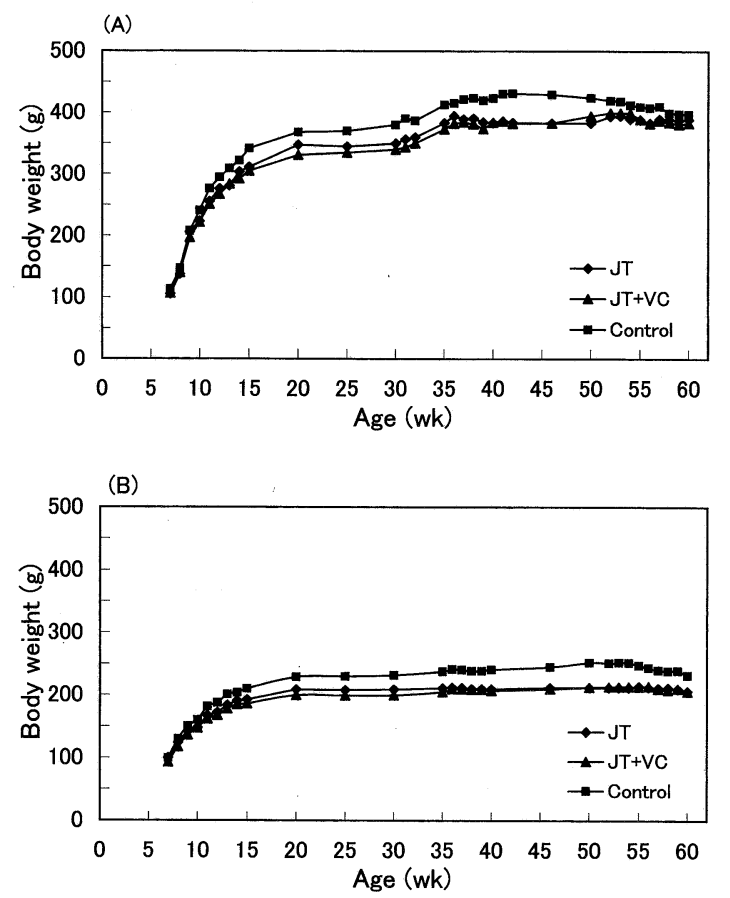

Fig. 1. Effects of salt and vitamin $\mathrm{C}$ on the body weight of SHR. The body weights of male (A) and female (B) SHR until 60 wk-old are shown. Salt and vitamin C were given to the rats by adding JT salt into the stock chow diet $(2.5 \mathrm{~g} / 100 \mathrm{~g}$ of diet) and by dissolving vitamin $\mathrm{C}$ into the drinking water $(500 \mathrm{mg} / 100 \mathrm{~mL}$ of water), respectively.

(A)

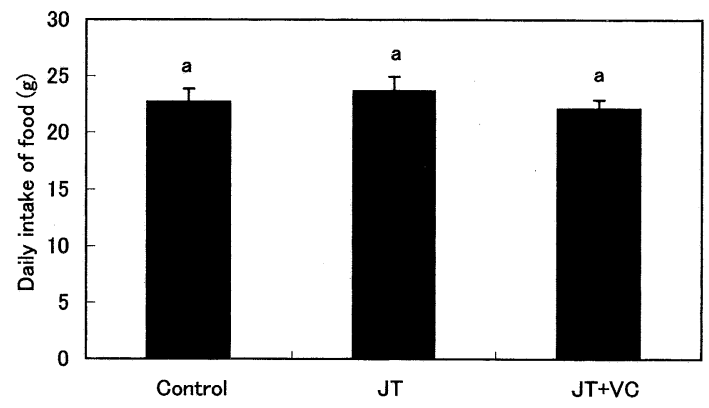

(B)

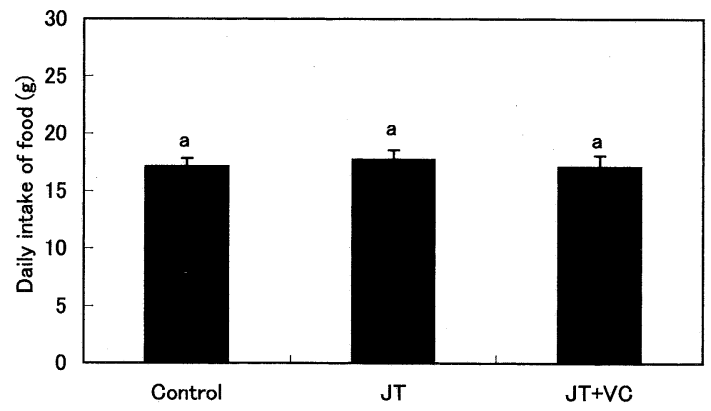

Fig. 2. Effects of salt and vitamin $\mathrm{C}$ on the daily food intake of SHR. The mean daily food intakes of male (A) and female (B) SHR until 60 wk-old are shown. The methods for giving the salt and vitamin $\mathrm{C}$ are described in the legend of Fig. 1. The columns show the mean \pm SD from 4 or 5 rats. Means within the same column not sharing a common superscript letter denote significant differences $(p<0.05)$. 

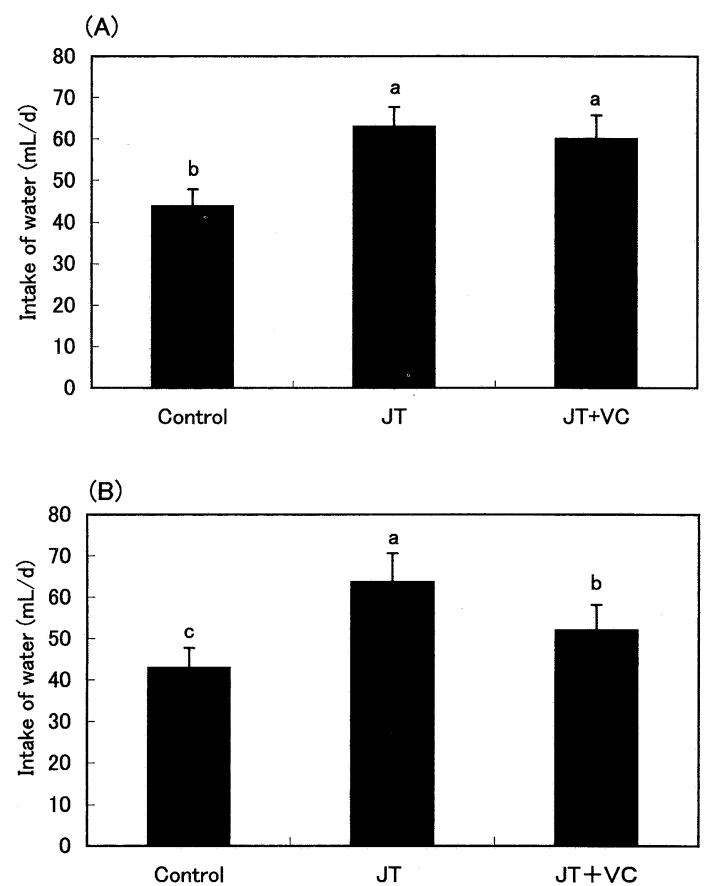

Fig. 3. Effects of salt and vitamin $\mathrm{C}$ on the daily water intake of SHR. The mean daily drinking water intakes of male (A) and female (B) SHR until 60 wk-old are shown. The methods for giving the salt and vitamin $\mathrm{C}$ are described in the legend of Fig. 1. The columns show the mean \pm SD from 4 or 5 rats. Means within the same column not sharing a common superscript letter denote significant differences $(p<0.05)$.

(A)

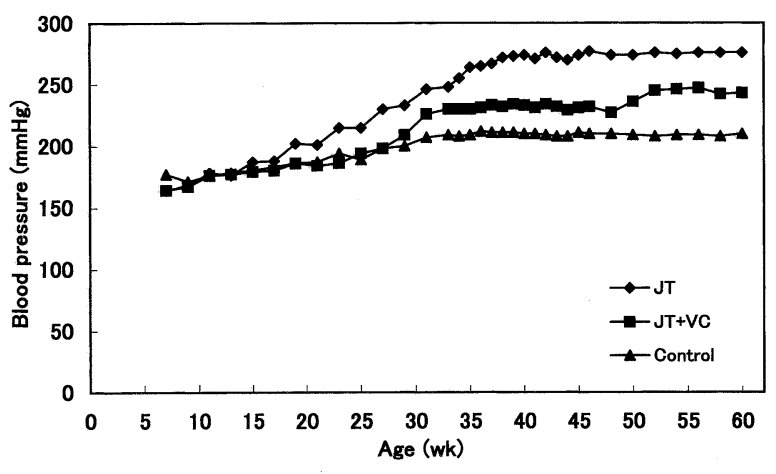

(B)

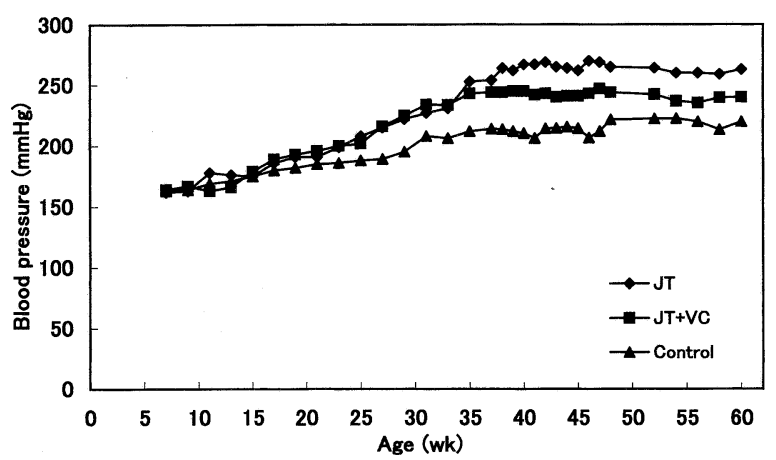

Fig. 4. Effects of salt and vitamin $\mathrm{C}$ on the systolic blood pressure (SBP) of SHR. The systolic blood pressures of male (A) and female (B) SHR until 60 wk-old are shown. The methods for giving the salt and vitamin $\mathrm{C}$ are described in the legend of Fig. 1.
(A)

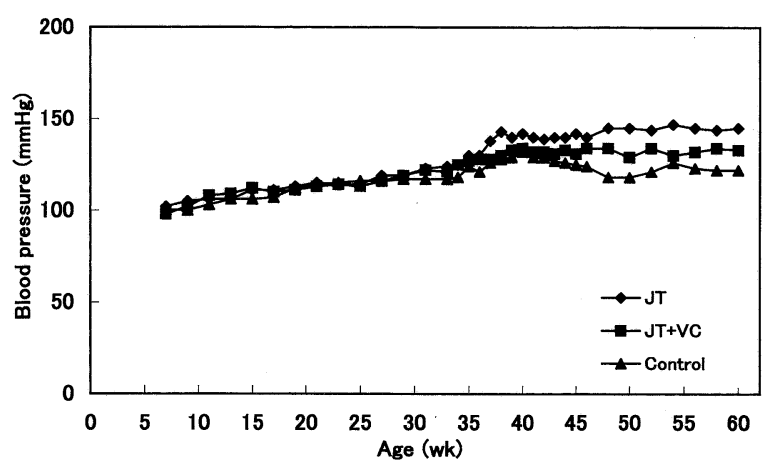

(B)

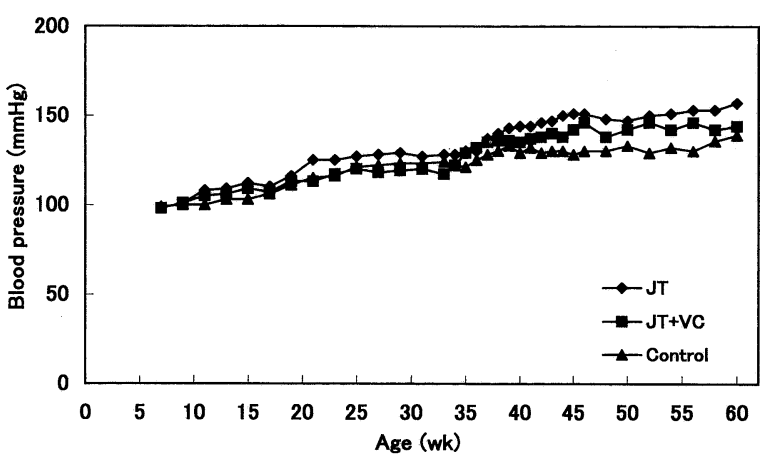

Fig. 5. Effects of salt and vitamin $\mathrm{C}$ on the diastolic blood pressure (DBP) of SHR. The diastolic blood pressures of male (A) and female (B) SHR until 60 wk-old are shown. The methods for giving the salt and vitamin $\mathrm{C}$ are described in the legend of Fig. 1.

(A)

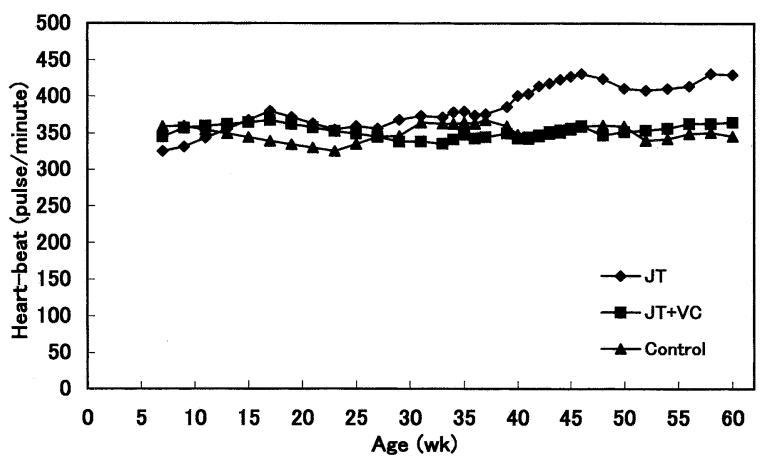

(B)

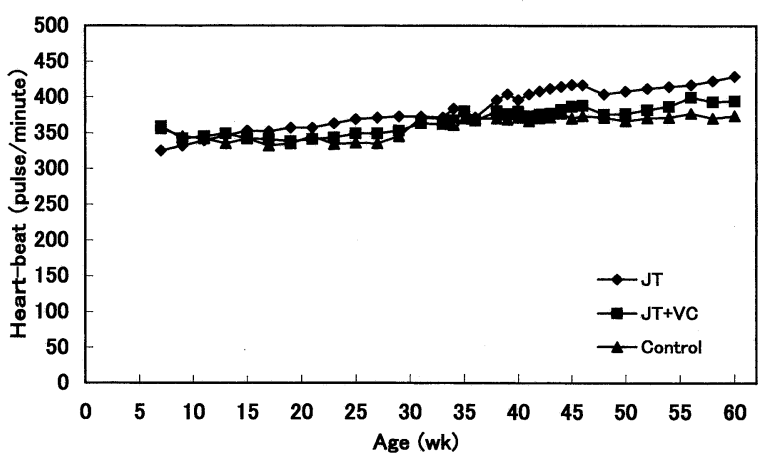

Fig. 6. Effects of salt and vitamin $\mathrm{C}$ on the heartbeat of SHR. The heartbeats of male (A) and female (B) SHR until 60 wk-old are shown. The methods for giving the salt and vitamin $\mathrm{C}$ are described in the legend of Fig. 1. 
Table 1. Effects of salt and vitamin $\mathrm{C}$ on the biological parameters in the urine of SHR rats.

(A)

\begin{tabular}{lcccc}
\hline & JT & JT + VC & Control & $\begin{array}{c}\text { Wistar } \\
\text { normal } \\
\text { rat }\end{array}$ \\
\hline Urobilinogen & normal & normal & normal & normal \\
Occult blood & ++ & + & - & - \\
Bilirubin & - & - & - & - \\
Ketone bodies & - & - & - & - \\
Glucose dextrose & - & - & - & - \\
Protein & ++++ & +++ & + & - \\
pH & 7 & 6 & 6 & 6 \\
WBC & +++ & +++ & +++ & - \\
Specific gravity & 1.015 & 1.025 & 1.020 & 1.020 \\
Ascorbic acid & - & + & - & - \\
\hline
\end{tabular}

(B)

\begin{tabular}{lcccc}
\hline & JT & JT+VC & Control & $\begin{array}{c}\text { Wistar } \\
\text { normal } \\
\text { rat }\end{array}$ \\
\hline Urobilinogen & normal & normal & normal & normal \\
Occult blood & ++ & + & - & - \\
Bilirubin & - & - & - & - \\
Ketone bodies & - & - & - & - \\
Glucose dextrose & - & - & - & - \\
Protein & ++++ & +++ & ++ & - \\
pH & 6.5 & 6 & 6 & 6 \\
WBC & +++ & +++ & +++ & - \\
Specific gravity & 1.015 & 1.025 & 1.020 & 1.020 \\
Ascorbic acid & - & + & - & - \\
& & & &
\end{tabular}

The values of male (A) and female (B) SHR rats were determined at $53 \mathrm{wk}$ of age using Tes-tape. The methods for giving the salt and vitamin $\mathrm{C}$ are described in the legend of Fig. 1. Wistar normal rats are also included to compare against the SHR rats. The values represent means from a given experimental group. The evaluations of these tests are as follows: urobilinogen (normal: $0-1 \mathrm{mg} / \mathrm{dL}$ ), occult blood (-: under 0.06 , +: $0.07-$ $0.15,++: 0.16-0.75 \mathrm{mg} / \mathrm{dL}$ ), bilirubin (-: under 0.5 $\mathrm{mg} / \mathrm{dL})$, ketone bodies (-: under $5 \mathrm{mg} / \mathrm{dL})$, glucose dextrose $(-$ : under $100 \mathrm{mg} / \mathrm{dL})$, protein $(-:$ under $10,+$ : 11-100, ++: 101-300, +++: 301-1,000, ++++: over $1,001 \mathrm{mg} / \mathrm{dL}$ ), WBC -: under $25,+++$ : over 501 cells $/ \mu \mathrm{L}$ ), and ascorbic acid (-: under $25,+$ : 26-60 $\mathrm{mg} / \mathrm{dL})$.

reaction for white blood cells (WBC) in their urine, three the SHR groups excreted a large amount of WBC. 4. Effects of salt and vitamin $C$ on the organ weight and biological function in the blood of SHR

All of the rats were dissected at $60 \mathrm{wk}$-old and the livers, stomaches, spleens, adrenal glands and kidneys were removed and weighed. The organ weights per 100 $\mathrm{g}$ of body weight are shown in Fig. 7. Significant differences in organ weight were not detected between the three groups, even in males versus females. The biolog- ical functions of SHR were determined by measuring the enzymatic activities and components in the blood, which indicated dysfunctions of the liver and blood vessels. The glucose (GLU), total cholesterol (T-cho) and urea nitrogen (BUN) in the blood were different between the three groups of SHR for both sexes as shown in Fig. 8. Further, the values for total bilirubin, ALT and AST of the female rats were not very different among the three groups of SHR. However, for male rats, the values were highest in group $\mathrm{A}$, and the values in group $\mathrm{B}$, which was given vitamin $\mathrm{C}$, decreased nearly to normal.

\section{DISCUSSION}

Dietary salt, especially $\mathrm{Na}^{+}$, has been thought to induce hypertension (22). Moreover, the simultaneous absorption of halogen ions like $\mathrm{Cl}^{-}$or $\mathrm{I}^{-}$with $\mathrm{Na}^{+}$has been shown to potentiate hypertension (20). For the prevention and medical treatment of hypertension, it has been generally accepted that limiting the dietary salt intake in daily life is important (25). On the other hand, a relationship between hypertension and vitamin $\mathrm{C}$ has been recently discovered.

Based on epidemiological studies, the effects of vitamin $\mathrm{C}$ on the prevention of hypertension and stroke have been assumed $(27,28)$. With respect to the clinical nutrition research on hypertension, vitamin $\mathrm{C}$ was reported to lower blood pressure and minimize variations in blood pressure (29). When hypertensive patients took $2 \mathrm{~g}$ of vitamin $\mathrm{C}$ per day, their blood pressure decreased significantly in all cases after $8 \mathrm{wk}$; by supplying vitamin $\mathrm{C}$, the blood pressure was lowered to 127 $\mathrm{mmHg}$ systolic and $75 \mathrm{mmHg}$ diastolic. Accordingly, the authors thought that vitamin $\mathrm{C}$ played a role in maintaining constant blood pressure (30). However, the mechanisms responsible for the physiological effects of vitamin $\mathrm{C}$ in depressing increased blood pressure remained obscure. To explore the cause of these effects, Yoshioka et al. studied SHR by given drinking water containing a $0.5 \% \mathrm{NaCl}$ solution. The rats developed a blood pressure of 180-190 mmHg over $120 \mathrm{~d}$, but when simultaneously giving $1,000 \mathrm{ppm}$ of vitamin $\mathrm{C}$ in food, the blood pressure decreased to $140 \mathrm{mmHg}$ (19). On the other hand, Horio et al. reported that vitamin C biosynthesis in rats is elevated while receiving xenobiotics like PCB (31). This elevation of activity was found to be lower in SHR than in normal rats (21).

In this experiment, more severe conditions for blood pressure were imposed, and the methods of administering the salt and vitamin $\mathrm{C}$ were changed. SHR rats given food containing $2.5 \% \mathrm{NaCl}$ developed a blood pressure of $270 \mathrm{mmHg}$ by 60 wk-old. The hypertensive rats with blood pressures over $250 \mathrm{mmHg}$ rarely moved in the cage all day. Accordingly, the hypertensive rats might contract heart disease, cerebrovascular disease or arteriosclerotic nephritis. The studies for blood-vessel disorders in the organs are subjects for the future. SHR rats given salt and vitamin $\mathrm{C}$ in their drinking water (V.C: $200 \mathrm{mg} / \mathrm{rat} / \mathrm{d}$ ) simultaneously had significantly decreased blood pressures under $250 \mathrm{mmHg}$. Even 
(A)
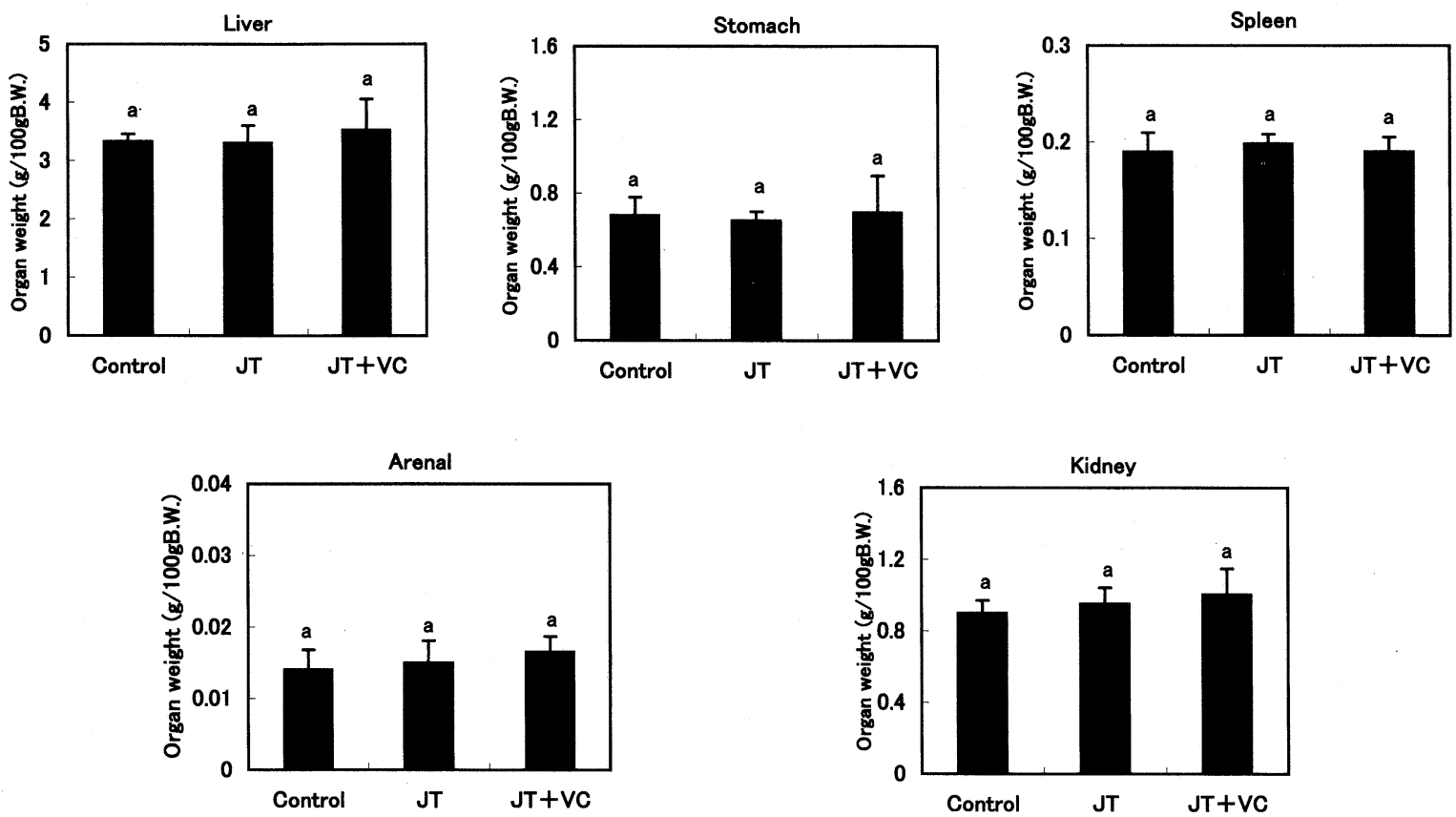

(B)
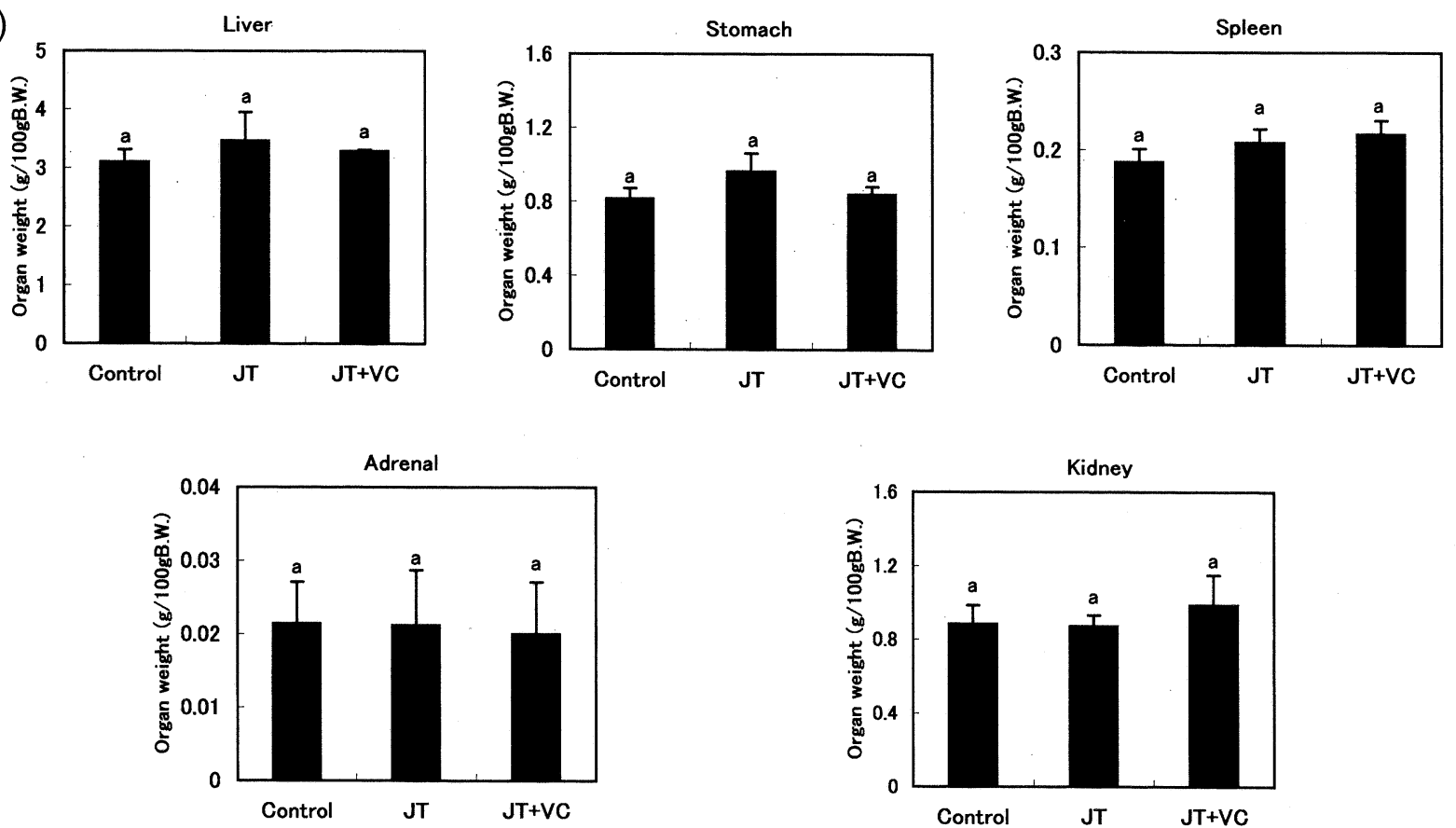

Fig. 7. Effects of salt and vitamin $\mathrm{C}$ on the organ weights of SHR. The organ weights ( $\mathrm{g} / 100 \mathrm{~g}$ body weight) of the liver, stomach, spleen, adrenal glands and kidneys of male (A) and female (B) SHR until 60 wk-old were determined. The methods for giving the salt and vitamin $\mathrm{C}$ are described in the legend of Fig. 1. The columns show the mean $\pm \mathrm{SD}$ from 4 or 5 rats. Means within the same column not sharing a common superscript letter denote significant differences $(p<0.05)$.

under conditions where the blood pressure was elevated to $270 \mathrm{mmHg}$ by high salt intake, vitamin $\mathrm{C}$ was found to decrease the blood pressure.

Based on this result, the mechanisms for controlling blood pressure due to vitamin $\mathrm{C}$ were hypothesized to be due to four main effects as described below. In general, the accumulation of $\mathrm{Ca}^{2+}$ in cells is thought to induce necrosis of the organs. In practice, organs with arterial sclerosis also have remarkably elevated $\mathrm{Ca}^{2+}$ levels in the cells. The absorption of $\mathrm{Ca}^{2+}$ in large excess into the cells and organs inhibits ATP synthesis, and causes the death of these cells. Vitamin $C$ works to attenuate the large $\mathrm{Ca}^{2+}$ excess from the organ cells, and also decrease $\mathrm{Ca}^{2+}$ levels in the blood and endothelial cells (32).

The second physiological effect of vitamin $\mathrm{C}$ for decreasing blood pressure was hypothesized as follows. Vitamin C may have activated the parasympathetic nerves and depressed the synthesis of the adrenocortical hormone. Vitamin C may reduce the hypertension caused by exogenous noradrenalin and atropine, which 
(A)
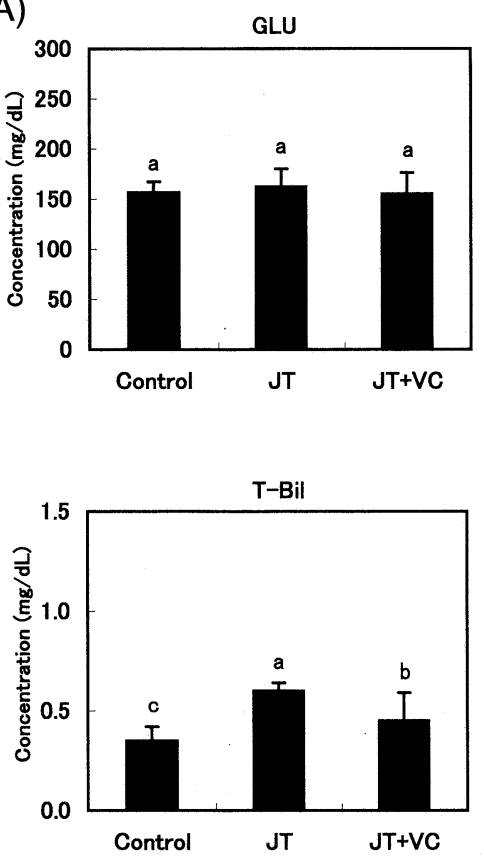

(B)
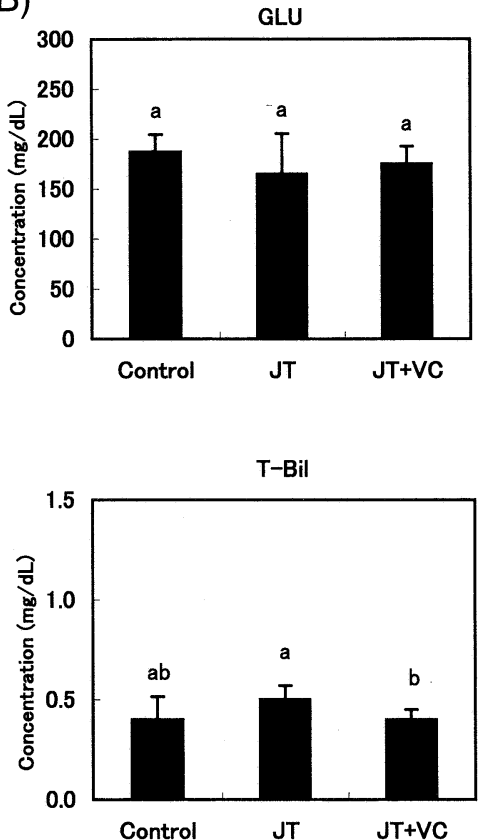
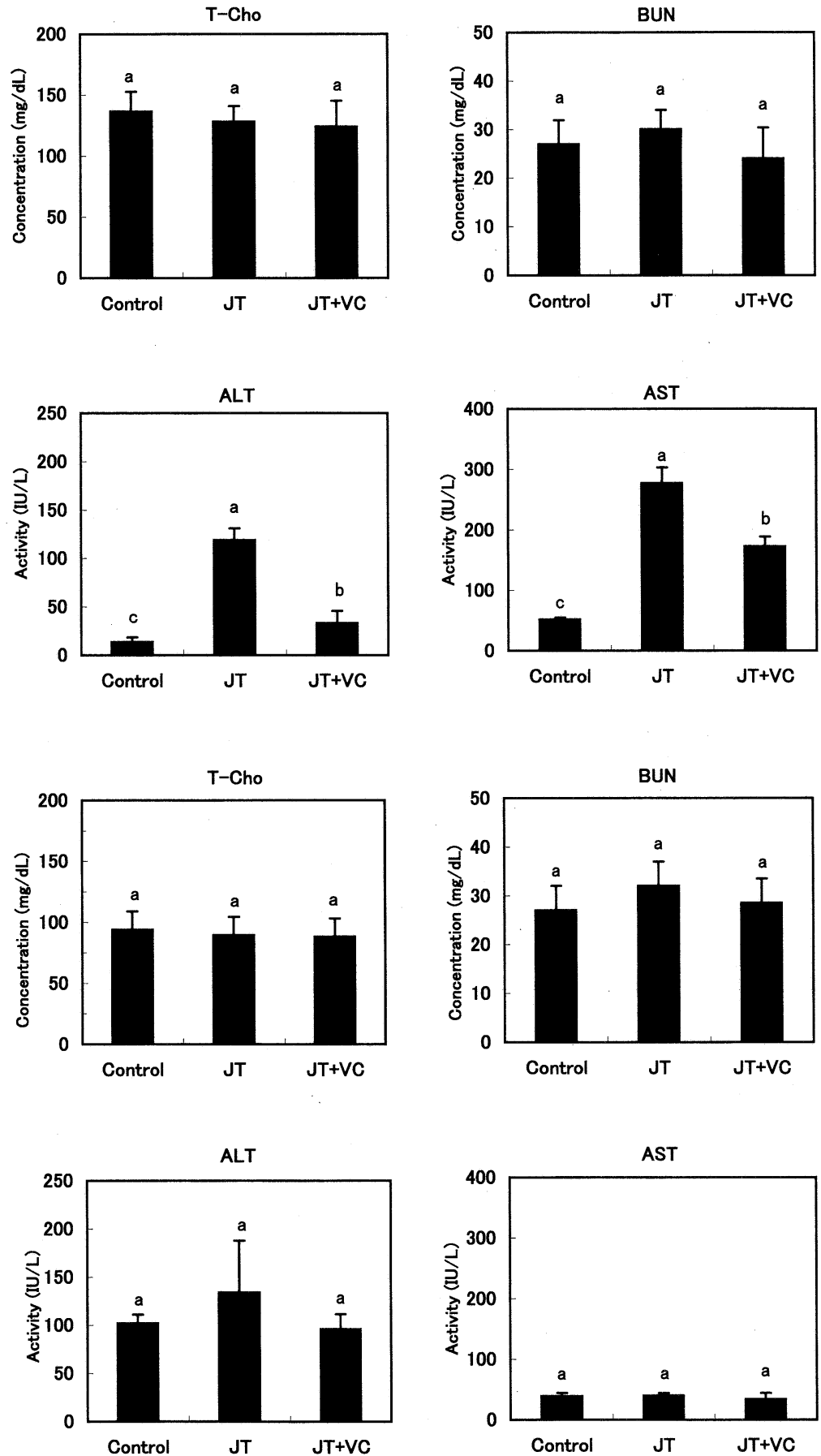

Fig. 8. Effects of salt and vitamin $\mathrm{C}$ on the biological functions of SHR. The glucose, total cholesterol, blood ulea nitrogen, total bilirubin alanine aminotransferase and aspartic acid aminotransferase levels in the blood of male (A) and female (B) SHR until 60 wk-old were determined. The methods for giving the salt and vitamin $C$ are described in the legend of Fig. 1. The columns show the mean \pm SD from 4 or 5 rats. Means within the same column not sharing a common superscript letter denote significant differences $(p<0.05)$.

is a blocker of the peripheral parasympathetic nerve. Under conditions where vitamin $C$ levels were reduced, it was reported that adrenocortical hormone was produced excessively (33) and resulted in a symptom like Cushing's syndrome (30).

The third function of vitamin $\mathrm{C}$ is thought to be related to reducing blood LDL-cholesterol. Hypercholesterolemia is one of the most significant risk factors of heart disease. Vitamin C was shown to decrease blood
LDL-cholesterol levels and to prevent arteriosclerosis, thereby decreasing the blood pressure (34). Galley et al. showed that some antioxidants worked as activators of NO synthase, and increased NO in blood and blood endothelial cells. Furthermore, antioxidants were shown to spare the oxidation of NO from active oxygen or free radicals (35). Therefore, a fourth function of vitamin C could be an activator of NO synthesis, or an inhibitor of NO destruction (36-38). In this experiment, AST and 
ALT enzyme activities in the blood of SHR rats were increased by dietary salt and then reduced by giving vitamin C. Moreover, the occult blood reaction was strong in SHR rats given salt, but SHR rats given salt and vitamin $\mathrm{C}$ simultaneously had lower values. Vitamin $C$ was found to protect against disorders of the liver and kidney. These effects were thought to be mainly due to the antioxidative effects of vitamin $\mathrm{C}$ in the liver and kidney cells.

\section{REFERENCES}

1) Tribble DC. 1999. Antioxidant consumption and risk of coronary heart disease: Emphasis on vitamin C, vitamin $\mathrm{E}$ and $\beta$-carotene. Circulation 99: 591-595.

2) Diaz MN, Frei B, Vita JA, Keaney JF. 1998. Antioxidants and atheroscleotic heart disease. N Engl J Med 337: 408-416.

3) Biesalsk HK. 1999. The role of antioxidative vitamins in primary and secondary prevention of coronary heart disease. Int J Vitam Nutr Res 69: 179-186.

4) Pietri S, Maurelli E, Drieu K, Culcasi M. 1997. Cardioprotective and antioxidant effects of the terpenoid constituents of Ginkgo biloba extract. J Mol Cell Cardiol 29: 733-742.

5) Stampter MJ, Hennekenz CH, Manson JE, Colditz GA, Rosner B, Willett WC. 1993. Vitamin E consumption and the risk of coronary heart disease in women. $N$ Engl J Med 328: 1444-1449.

6) Ginter E. 1981. The influence of vitamin C on lipid metabolism. In: Vitamin C (Counsell JN, Hornig DH, eds), p. 299-347. Applied Science Publishers, New York.

7) Oda H, Yamashita K, Sasaki S, Horio F, Yoshida A. 1987. Long-term effects of dietary polychlorinated biphenyl and high level of vitamin $\mathrm{E}$ on ascorbic acid and lipid metabolism in rats. J Nutr 117: 1217-1223.

8) Adams MR, Kinlay S, Blake GJ, Orford JL, Ganz P, Selwyn AP. 2000. Atherogenic lipids and endothelial dysfunction: Mechanisms in the genesis of ischemic syndromes. Ann Rev Med 51: 149-167.

9) Richard CM, Sato H, David SL, Ishi T, Bannai S, Giovanni EM. 1999. Induction of antioxidant stress proteins in vascular endothelial and smooth muscle cells: Protective action of vitamin $\mathrm{C}$ against atherogenic lipoproteins. Free Rad Res 31: 309-318.

10) Yoshioka M, Matsushita T, Chuman Y. 1998. Inverse association of serum ascorbic acid level and blood pressure of rats of hypertension in male adults aged 30-39 years. Int J Vst Nutr Res 54: 343-347.

11) Mc Carrron DA, Morris CD, Henry HJ, Stanton JL. 1984. Blood pressure and nutrient intake in the United States. Science 224: 1392-1398.

12) Bates CJ, Walmsley CM, Prentice A, Finch S. 1998. Does vitamin $\mathrm{C}$ reduce blood pressure? Results of a large study of people aged 65 or older. J Hypertens 16: 925932.

13) Guidelines for the Management of Mild Hypertension: Memorandum from a World Health Organization/International Society of Hypertension Meeting. 1993. Guideline Sub-committee. J Hypertens 11: 905-918.

14) Duffy SJ, Gokce N, Holbrook H, Huang A, Frei B, Keaney JF, Vita JA. 1999. Treatment of hypertension with ascorbic acid. Lancet 354: 2048-2049.

15) Moran JP, Cohen L, Greene JM. 1993. Plasma ascorbic acid concentrations relate inversely to blood pressure in human subjects. Am J Clin Nutr 57: 59-64.

16) Toohey L, Harris MA, Allen KG, Melby CL. 1996. Plasma ascorbic acid concentrations and related to cardiovascular risk factors in African-Americans. J Nutr 126: 121-128.

17) Kobori Y. 1960. Experimental studies for the exchange of blood pressure of ascorbic acid. Hirosaki Med 12: 265-269.

18) Rimm EB, Stampter MJ, Ascherio A, Giovannucci E, Colditz GA, Willett WC. 1993. Vitamin E consumption and risk of coronary heart disease in men. N Engl J Med 328: $1450-1456$.

19) Yoshioka M, Aoyama K, Matsushita T. 1985. Effect of ascorbic acid on blood pressure and ascorbic acid metabolism in spontaneously hypertensive rats (SH rats). Int J Vit Nutr Res 55: 301-307.

20) Murakami T, Yamamoto K, Sirasaka N, Yoshizumi H. 1996. Protective effect of a fish diet against dysfunction of endothelial cells in vessel resistance in stroke-prone spontaneously hypertensive rats. J Jpn Soc Nutr Food Sci 49: 23-28.

21) Kato S. 2001. Effect of chloride on stroke incident and blood pressure in salt-sensitive hypertensive rats. J Jpn Soc Nutr Food Sci 54: 147-153

22) Menely GR, Tucker RG, Darby WJ, Suerbach SN. 1953. Chronic sodium chloride toxicity in the albino rat. J Exp Med 98: 71-79.

23) Kurtz TW, Al-Bander HA, Morris RC Jr. 1987. "Salt-sensitive" essential hypertension in men. Is the sodium ion alone important? N Engl J Med 317: 1043-1048.

24) Whitescarver SA, Ott CE, Jackson BA, Guthrie GP Jr, Kotchem TA. 1984. Salt-sensitive hypertension: Contribution of chloride. Science 223: 1430-1432.

25) Sharma AM, Schattenfroh S, Thiede HM, Oelkers W, Distler A. 1992. Effect of sodium salts on pressure reactivity in salt-sensitive men. Hypertension 19: 541-548.

26) Duncan DB. 1955. Multiple range and multiple F test. Biometrics 11: 1-42.

27) Sakai N, Yokoyama T, Date C, Yoshiike N, Matsumura Y. 1998. An inverse relationship between serum vitamin C and blood pressure in a Japanese community. J Nutr Sci Vitaminol 44: 853-867.

28) Moran JP, Cohen L, Greene JM, Xu G, Feldman EB, Hames CG, Feldman DS. 1993. Plasma ascorbic acid concentrations relate inversely to blood pressure in human subjects. Am J Clin Nutr 57: 213-217.

29) Jacques PR. 1992. A cross-sectional study of vitamin C intake and blood pressure in the elderly. Int J Vit Nutr Res 62: 252-255.

30) Yoshioka M. 1990. Vitamin C and pressure. Monthly Food Chem 3: 38-45.

31) Horio F, Shibata T, Makino S, Machino S, Hayashi Y, Hattori T, Yoshida A. 1993. UDP glucuronosyltransferase gene expression is involved in the stimulation of ascorbic acid biosynthesis by xenobiotics in rats. J Nutr 123: 2075-2084.

32) LeVine H, Bronson DD, Khouri R, Sahyoun NE. 1983. Ascorbic acid is an endogenous cytosolic inhibitor of ATP-supported rat liver mitochondrial calcium transport. J Biol Chem 258: 14954-14959.

33) Horio F, Ozaki K, Yoshida A, Makino S, Hayashi Y. 1985. Requirement for ascorbic acid in rat mutant unable to synthesize ascorbic acid. J Nutr 115: 1630-1640.

34) Bordia AK. 1980. The effect of vitamin C on blood li- 
pids, fibrinolytic activity and platelet adhesiveness in patient with coronary artery disease. Atherosclerosis 35 : 181-187.

35) Galley HF, Thoronton J, Howdle PD, Walker BE, Webster NR. 1997. Combination oral antioxidant supplementation reduces blood pressure. Clin Sci 92: 361-365.

36) Huang A, Vita JA, Venema RC, Keaney Jr JF. 2000. Ascorbic acid enhances endothelial nitric-oxide synthase activity by increasing intracellular tetrahydro- biopterin. J Biol Chem 275: 17399-17406.

37) Horio F, Hayashi K, Kiyama K. 2001. Does ascorbic acid reduce hypertension (Relationship between No and AsA)? Vitamin 75: 510-511.

38) Carlsson S, Wiklund NP, Engstrand L, Weitzberg E, Lundberg JON. 2001. Effect of pH, nitrite, and ascorbic acid on nonenzymatic nitric oxide generation and bacterial growth in urine. Nitric Oxide. Biol Chem 5: 580-586. 